\title{
The Appendix Is Not Always Alone in Amyand's Hernia
}

\author{
Sherif Monib ${ }^{1}$, Hany F. Habashy ${ }^{2}$ \\ 1. Breast Surgery, West Hertfordshire Hospitals NHS Trsut, St. Albans and Watford General Hospitals, London, GBR 2. \\ Surgical Oncology, Fayoum University, Faculty of Medicine, Fayoum, EGY
}

Corresponding author: Sherif Monib, sherif.monib@nhs.net

\begin{abstract}
An inguinal hernia is one of the most common surgical conditions accounting for both elective as well as acute admissions. Amyand's hernia is a rare entity of inguinal hernia, which represents a very small percentage of all inguinal hernias. While in most cases it is an incidental finding encountered during routine repair of an inguinal hernia, in other cases, it might be the reason for acute presentation. We are presenting a case of a six-week-old male who was found intraoperatively to have not only the appendix but also the caecum in the hernia sac. We believe that a preoperative groin ultrasound scan would aid clinical diagnosis and facilitate surgical planning in these cases.
\end{abstract}

Categories: Pediatrics, General Surgery

Keywords: congenital inguinal hernia - amyand's hernia- caecum- appendix

\section{Introduction}

An inguinal hernia is one of the common conditions encountered in infants, which require early diagnosis and prompt management due to the risk of incarceration and strangulation that can lead to significant morbidities [1]. Claudius Amyand was a French surgeon who first described the presence of the appendix in the hernia sac in a patient who had appendicitis in 1735 [2]. While the classic definition of Amyand's hernia is the presence of the appendix in the hernia sac [3], other variants include the presence of the appendix as well as the caecum or even the appendix the caecum and the terminal ileum; also, the appendix might be normal, inflamed, incarcerated, strangulated or even perforated. Clinical diagnosis of Amyand's hernia without the aid of imaging modalities can be difficult due to its rarity, as well as the presence of different variants.

Review began $12 / 11 / 2020$ Review ended 12/21/2020 Published 12/26/2020

○ Copyright 2020

Monib et al. This is an open access article distributed under the terms of the Creative Commons Attribution License CC-BY 4.0., which permits unrestricted use, distribution, and reproduction in any medium, provided the original author and source are credited.

\section{Case Presentation}

We present a case of a six-week-old male infant, born at 39-week gestation, who was brought by his mother to the emergency department with right groin tender swelling, with no history of fever, vomiting, abdominal distension, or diarrhea. His vital signs were normal, and general examination was unremarkable. Abdominal examination revealed no clinical signs of bowel obstruction; groin examination revealed a $40 \mathrm{~mm}$ irreducible right-sided inguinal hernia with no signs of strangulation; the scrotal examination was normal (Figure 1). 


\section{Cureus}

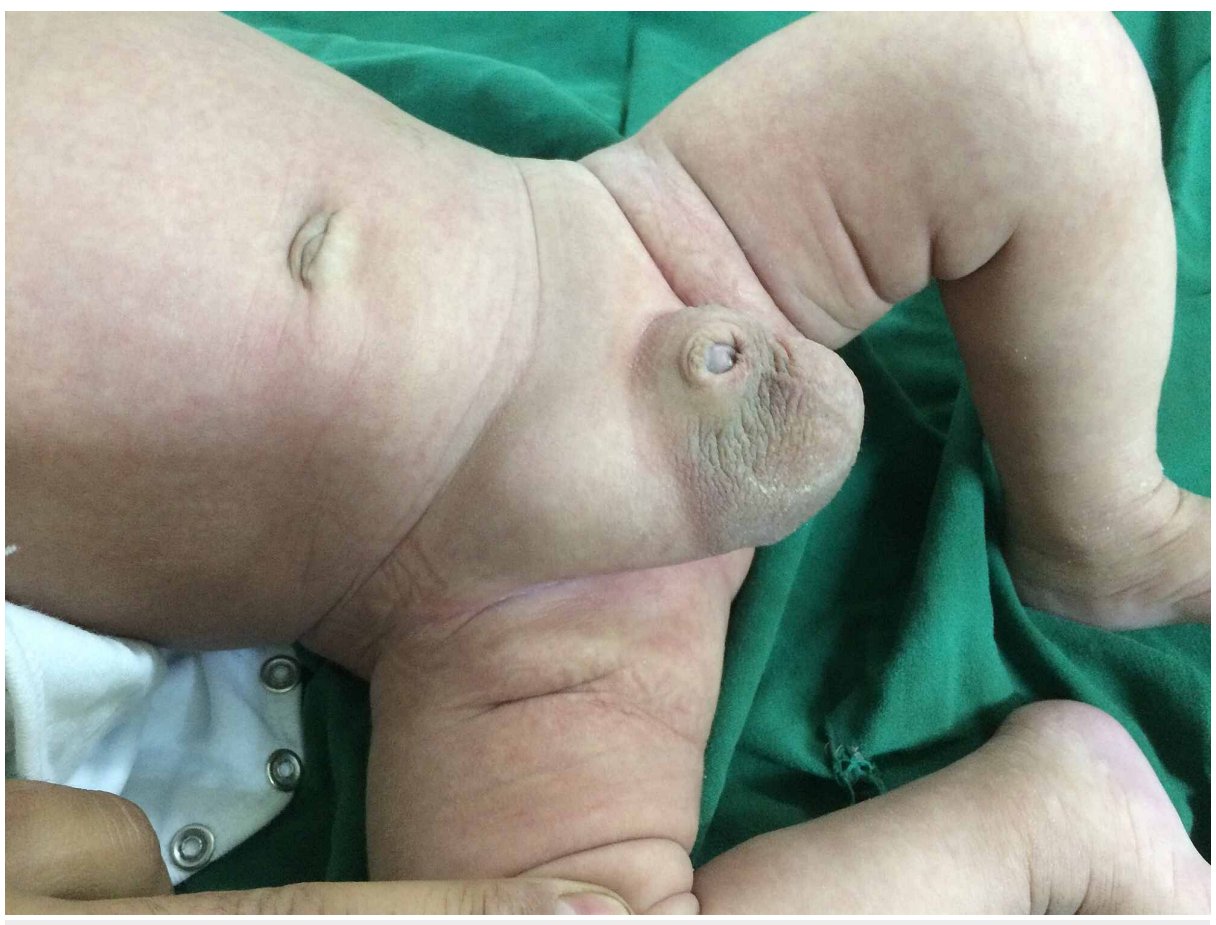

FIGURE 1: Preoperative picture showing right groin inguinal hernia seen by inspection

Routine blood tests including full blood count, C-reactive protein (CRP), liver and kidney functions were all within a normal range, and there was no clinical indication for any imaging modality. Our provisional diagnosis was an incarcerated inguinal hernia. Since these types of hernias are better repaired as soon as diagnosed to avoid strangulation, an attempt to repair the hernia through a standard groin incision revealed a viable caecum and long non-inflamed appendix in the hernia sac (Figure 2).

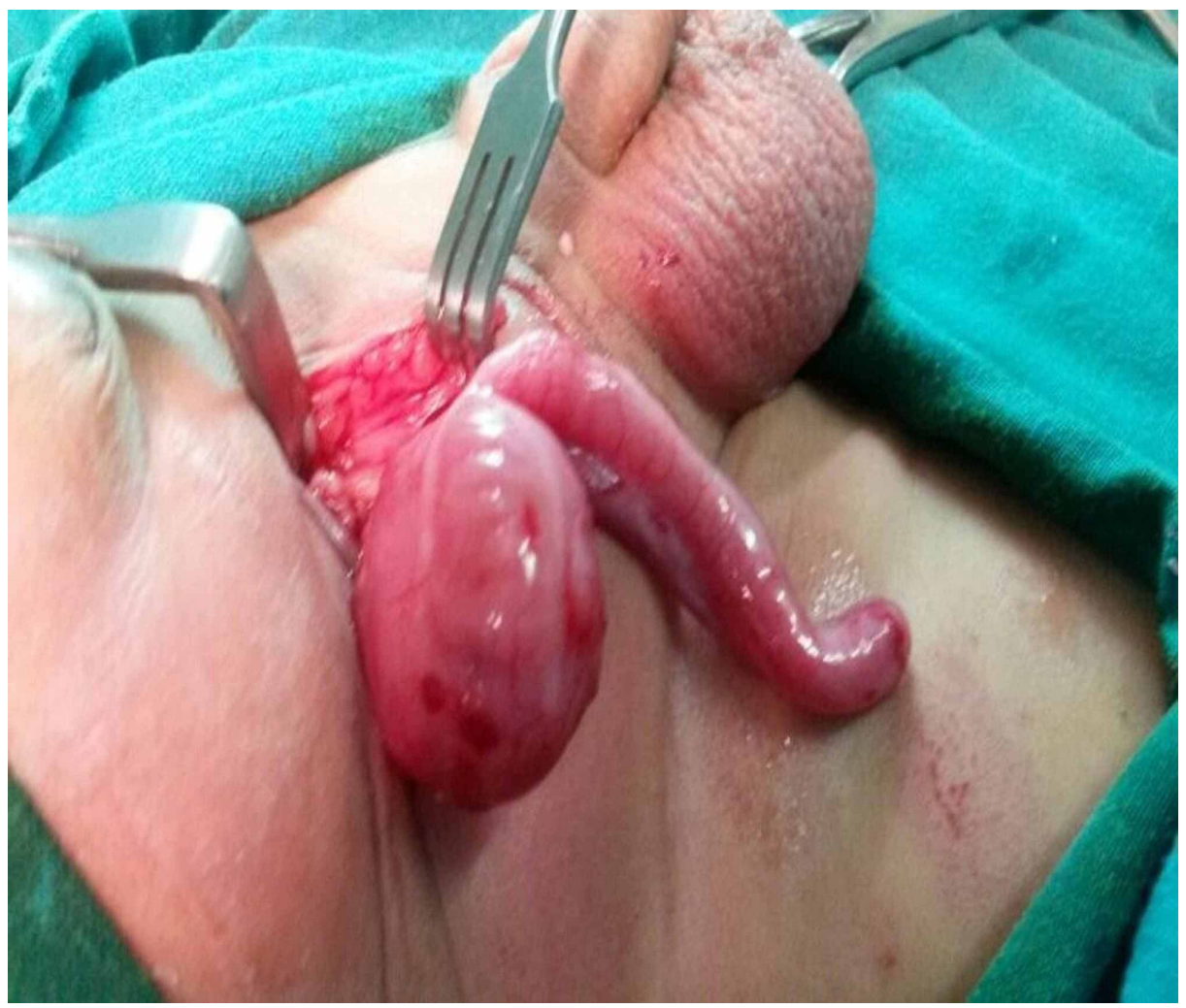

FIGURE 2: Intraoperative picture showing the caecum and the appendix 
Herniotomy was carried out; the patient had an uneventful recovery, was discharged home the following day, and was seen in the clinic six weeks after, and no signs of postoperative complications were noted.

\section{Discussion}

A congenital inguinal hernia is considered one of the most common surgical diagnoses, with $4 \%$ of the pediatric population diagnosed with an inguinal hernia [4], and a cumulative incidence from birth to 15 years of age of $6.62 \%$ in males and $0.74 \%$ in females [5].

Amyand's hernia is only seen in 1\% of all inguinal hernias [3], in most cases reported in males, exclusively on the right side, with exceptions of intestinal malrotation and situs inversus totalis - the conditions reported on the left side [6]. In some rare cases, the appendix can be accompanied by the cecum, omentum, terminal ileum, Meckel diverticulum, urinary bladder, or ovarian and fallopian tube in females [7, 8].

Due to the rarity of the condition and unclear management guidelines, Losanoff and Basson created a classification scale to identify and treat Amyand's hernias based on intraoperative findings $[9,10]$ (Table 1).

\begin{tabular}{|l|l}
\hline Classification & Description \\
\hline Type 1 & Normal appendix in an inguinal hernia \\
Type 2 & Acute appendicitis in an inguinal hernia, without abdominal sepsis \\
Type 3 & $\begin{array}{l}\text { Acute appendicitis in an inguinal hernia, with abdominal wall or } \\
\text { peritoneal sepsis }\end{array}$
\end{tabular}

Type 4 Acute appendicitis in an inguinal hernia, with abdominal pathology

\section{Surgical management}

Hernia reduction, mesh repair

Appendectomy, primary repair of hernia without mesh

Laparotomy, appendectomy, primary repair without mesh

Manage as Type 1-3, investigate pathology as needed

\section{TABLE 1: Losanoff and Basson Amyand's hernia management classification}

Although there has always been an association between prematurity and incidence of strangulation [11], Chang et al., in their large cohort, which comprised 1,000,000 patients found that incarceration was related neither to prematurity nor the waiting time for surgery [5].

CT scan is considered an accurate imaging modality for preoperative diagnosis of Amyand's hernia in adults. Also, an ultrasound scan can show specific features of Amyand's hernia as the presence of a noncompressible, dilated, blind-ending bowel loop with a luminal diameter of more than $7.2 \mathrm{~mm}$, within the inguinal canal with or without surrounding inflammation, which can be used for preoperative diagnosis in pediatric patients [12].

In our case, a type 1 Amyand's hernia was only diagnosed intraoperatively. Given the normal appearance of the caecum and the long appendix, herniotomy was carried out with a good outcome. In hindsight, we think that a quick inguinal ultrasound scan would have provided more insight about the condition before the operation.

\section{Conclusions}

Amyand's hernia is a rare entity, with a good range of variant clinical presentations and management. Clinical diagnosis without the aid of imaging modalities is not always accurate; therefore, we recommend performing an ultrasound scan at presentation to give an idea about the hernia sac content as well as possible strangulation, which will aid surgical planning.

\section{Additional Information \\ Disclosures}

Human subjects: Consent was obtained by all participants in this study. Conflicts of interest: In compliance with the ICMJE uniform disclosure form, all authors declare the following: Payment/services info: All authors have declared that no financial support was received from any organization for the submitted work. Financial relationships: All authors have declared that they have no financial 
relationships at present or within the previous three years with any organizations that might have an interest in the submitted work. Other relationships: All authors have declared that there are no other relationships or activities that could appear to have influenced the submitted work.

\section{References}

1. Piedade C, Reis Alves J: Amyand's hernia in a 6-week-old infant: a delayed diagnosis . Case Rep Pediatr. 2013, 2013:1-3. 10.1155/2013/758171

2. Claudius A: Of an inguinal rupture, with a pin in the appendix caeci, incrusted with stone; and some observations on wounds in the guts. Philos Trans R Soc. 1735, 39:329-336. 10.1098/rstl.1735.0071

3. Cankorkmaz L, Ozer H, Guney C, Atalar MH, Arslan MS, Koyluoglu G: Amyand's hernia in the children: a single center experience. Surgery. 2010, 147:140-143. 10.1016/j.surg.2009.09.038

4. Erdoğan D, Karaman İ, Aslan MK, Karaman A, Çavuşoğlu YH: Analysis of 3776 pediatric inguinal hernia and hydrocele cases in a tertiary center. J Pediatr Surg. 2013, 48:1767-1772. 10.1016/j.jpedsurg.2012.09.048

5. Chang SJ, Chen JC, Hsu CK, Chuang FC, Yang SD: The incidence of inguinal hernia and associated risk factors of incarceration in pediatric inguinal hernia: a nation-wide longitudinal population-based study. Hernia. 2016, 20:559-563. 10.1007/s10029-015-1450-x

6. Michalinos A, Moris D, Vernadakis S: Amyand's hernia: a review. Am J Surg. 2014, 207:989-995. 10.1016/j.amjsurg.2013.07.043

7. Nicola SM, Mora GM, Stock LR, et al.: Amyand hernia. Report of one case . Rev Chil Cirugía. 2007, 59:142144.

8. Mahajan A, Pawar P, Luther A, Haque P: Right sided Amyand's hernia: a rare case report . Int Surg J. 2014, 1:43-44. 10.5455/2349-2902.isj20140514

9. Losanoff JE, Basson MD: Amyand hernia: what lies beneath--a proposed classification scheme to determine management. Am Surg. 2007, 73:1288-1290.

10. Losanoff JE, Basson MD: Amyand hernia: a classification to improve management. Hernia. 2008, 12:325326. 10.1007/s10029-008-0331-y

11. Uemura S, Woodward AA, Amerena R, Drew J: Early repair of inguinal hernia in premature babies . Pediatr Surg Int. 1999, 15:36-39. 10.1007/s003830050507

12. Kathar Hussain Mr, Kulasekeran N : A case report of Amyand hernia-radiological diagnosis and literature review. Egypt J Radiol Nucl Med. 2020, 51:226. 10.1186/s43055-020-00346-4 